Article

\title{
Can Data Assimilation of Surface PM2.5 and Satellite AOD Improve WRF-Chem Forecasting? A Case Study for Two Scenarios of Particulate Air Pollution Episodes in Poland
}

\author{
Małgorzata Werner*, Maciej Kryza ${ }^{(D)}$ and Jakub Guzikowski ${ }^{(D)}$ \\ Department of Climatology and Atmosphere Protection, University of Wroclaw, ul. Kosiby 8, \\ 51-621 Wroclaw, Poland; maciej.kryza@uwr.edu.pl (M.K.); jakub.guzikowski@uwr.edu.pl (J.G.) \\ * Correspondence: malgorzata.werner@uwr.edu.pl
}

Received: 13 August 2019; Accepted: 9 October 2019; Published: 12 October 2019

\begin{abstract}
Based on the Weather Research and Forecasting model with Chemistry (WRF-Chem) model and Gridpoint Statistical Interpolation (GSI) assimilation tool, a forecasting system was used for two selected episodes (winter and summer) over Eastern Europe. During the winter episode, very high particular matter (PM2.5, diameter less than $2.5 \mu \mathrm{m}$ ) concentrations, related to low air temperatures and increased emission from residential heating, were measured at many stations in Poland. During the summer episode, elevated aerosol optical depth (AOD), likely related to the transport of pollution from biomass fires, was observed in Southern Poland. Our aim is to verify if there is a relevant positive impact of surface and satellite data assimilation (DA) on modeled PM2.5 concentrations, and to assess whether there are significant differences in the DA's impact on concentrations between the two seasons. The results show a significant difference in the impact of surface and satellite DA on the model results between the summer and winter episode, which to a large degree is related to the availability of the satellite data. For example, the application of satellite DA raises the factor of two statistic from 0.18 to 0.78 for the summer episode, whereas this statistic remains unchanged (0.71) for the winter. The study suggests that severe winter air pollution episodes in Poland and Eastern Europe in general, often related to the dense cover of low clouds, will benefit from the assimilation of surface observations rather than satellite data, which can be very sparse in such meteorological situations. In contrast, the assimilation of satellite data can have a greater positive impact on the model results during summer than the assimilation of surface data for the same period.
\end{abstract}

Keywords: data assimilation; AOD; Moderate Resolution Imaging Spectrometer (MODIS); PM2.5; WRF-Chem

\section{Introduction}

Air pollution forecasts are used by policy makers and society at large to assess air quality for the forthcoming hours and days and to make decisions on future behavior. This is especially important for correctly predicting high pollution concentrations, as it allows prevention of the harmful effects of pollutants on human health [1]. However, while chemical transport models perform relatively well in average air quality conditions, they often fail when it comes to high air pollution concentrations [2]. Therefore, much effort is needed to improve forecasts of severe air quality episodes.

Some European countries in Eastern or Central Europe (e.g., Poland) have serious problems with air quality. High concentrations of particulate matter (PM) in winter are often related to high coal and wood combustion for residential heating [3,4]. Meteorological conditions (i.e., low air temperature and anticyclone systems), provide favorable conditions for the accumulation of air pollution and 
the deterioration of air quality, rendering it harmful to people. Short- and long-term exposure to atmospheric aerosols is often linked to health problems, including respiratory and cardiovascular diseases and increased mortality [5,6]. Particles with a diameter less than $10 \mu \mathrm{m}$ (PM10) can penetrate the lower airways, while fine particulate matter (PM2.5, diameter less than $2.5 \mu \mathrm{m})$ is thought to constitute a notable health risk, since it can be inhaled more deeply into the lungs [7]. It has also been shown that air pollution, including PM, can influence the allergenicity of pollen, which might be of importance during the vegetation season [8]. Chemical air pollution may interact with airborne allergens, enhancing the risk of atopic sensitization and exacerbation of symptoms in sensitized subjects as well as asthma and asthma-like symptoms. The combined exposure to air pollutants and allergens has a synergistic or additive effect on asthma and allergies [9]. This might be especially relevant in Europe, as it is estimated that the overall prevalence of hay fever among Europeans is approximately $15 \%-20 \%$ [10]. More than 20\% of Poles suffer from hazel and alder allergies [11].

Air pollution forecasts can be initialized using raw concentrations of chemical species obtained from the previous day's forecast or these concentrations can be modified by the application of data assimilation (DA). DA is used for the integration of available observations into models in order to produce aerosol concentration fields, which are then used to provide model initial conditions to improve forecasts. Previous publications have shown that initial conditions play an important role in chemical forecasting [12-18]. A review of the current status of data assimilation in atmospheric chemistry models has been presented by Bocquet et al. [19].

The three-dimensional variational method (3D-Var) is one of the most popular data assimilation approaches. A 3D-Var scheme iteratively minimizes the cost function that depends on error covariance matrices. The observations are collected at analysis time with no model integration required, therefore the analysis increment does not evolve in time [20,21]. Of the widely used data assimilation schemes, the 3D-Var scheme is the most computationally efficient [12]. The 3D-Var method has recently been tested for Poland by Werner et al. [22]. They used 3D-Var to assimilate surface PM2.5 observations to the Weather Research and Forecasting with Chemistry (WRF-Chem) model, thereby showing that the assimilation of surface PM2.5 has a positive impact on modeled PM2.5 and PM10 concentrations over Poland. The assimilation of surface observations can be accompanied by satellite data assimilation. The advantage of surface observations is a high temporal resolution (usually $1 \mathrm{~h}$ ) and a high certainty of observation availability but their disadvantage is discrete spatial distribution. On the contrary, satellite data can have much larger spatial coverage, however their availability is highly dependent on things such as meteorological conditions.

The number of parallel experiments with assimilation of satellite aerosol optical depth (AOD) and surface PM2.5 observations to WRF-Chem, both individually and simultaneously, is limited. This has been previously done for the continental United States by Schwartz et al. [16]. In general, their results have shown that assimilating both AOD and PM2.5 observations separately and together can help reduce a negative bias. Such an experiment with 3D-Var assimilation of both surface and satellite observations to WRF-Chem has not previously been published for a European country and in general there is a limited number of studies on assimilation of particulate matter (PM) observations to chemical transport models (CTMs) over Europe. Therefore, we believe that our study will provide valuable insight on surface and satellite data assimilation for areas characterized by low air quality in Europe. This is of special importance for large areas of Central Europe, which suffer from high emissions from residential combustion during the heating season. These emission conditions are specific to this part of the world, with a large share of coal used for residential heating. For these conditions data assimilation has not been thoroughly tested so far.

In this paper, we applied the 3D-Var data assimilation technique to improve PM2.5 forecasts for two specific periods. The first period was winter 2017, when high PM2.5 concentrations were observed in Poland because of high emissions from residential combustion. Previous papers have already exposed the poor performance of PM2.5 and PM10 forecasts for this period (e.g., [23]). This raises the question of whether the forecasting system, based on the WRF-Chem model, can be improved for 
such cases by the application of data assimilation techniques and the sources of measurements that contribute the most. The second period was summer 2015. For this case, elevated AOD was observed over Central Europe as a result of biomass burning emissions, particularly over Ukraine and Russia. These areas are outside of the model forecasting domain and the emission processes are not directly included in the model simulation. For both cases, we quantify the impact of separate and combined assimilation of surface PM2.5 measurements and satellite AOD on PM2.5 concentrations forecasts.

\section{Materials and Methods}

\subsection{The Episodes}

We chose two episodes that differ in terms of prevailing emission sources and meteorological conditions, both of which were previously identified from poor error statistics. Both episodes have previously been discussed in the literature [23,24]. The winter episode covered the period from 11-25 February 2017. In the first half of the winter episode, high concentrations of PM2.5, exceeding $100 \mu \mathrm{g} \mathrm{m}^{-3}$ at a number of measuring sites, were observed (mean concentration for the winter period of 2017 was $38 \mu \mathrm{g} \mathrm{m}^{-3}$ with standard deviation (SD) equal to $11 \mu \mathrm{g} \mathrm{m}^{-3}$ ). This was related to a specific meteorological situation favorable for the accumulation of atmospheric pollutants-Poland was under the influence of a high-pressure system, with the center located over Eastern Poland and Belarus. Low air temperatures during the night and low wind speeds observed during the episode were responsible for the increased emission of atmospheric pollutants from domestic heating and their accumulation close to the emission sources. Over the second half of this period, the high-pressure system moved southward. This led to the advection of warm air masses from the south of Europe, a rapid increase of minimum air temperatures in Poland, and a higher wind speed which was unfavorable for the accumulation of atmospheric pollutants.

The summer episode covered the period from 1-20 August 2015. This month was selected as it had been previously analyzed in detail by Szkop and Pietruczuk [24]. This was an unusually warm month in Poland, with several episodes of elevated AOD observed in Southern Poland, especially during the first half of the month. Back trajectory analysis with the HYSPLIT (Hybrid Single Particle Lagrangian Integrated Trajectory) model, presented by Szkop and Pietruczuk [24], suggests that the source region for aerosols measured during the first half of this month was located to the south and east of Poland, most likely over Ukraine, where an area with many biomass fires was located. The mean measured surface PM2.5 concentration over Poland was $14 \mu \mathrm{g} \mathrm{m}^{-3}$ (SD equal to $5 \mu \mathrm{g} \mathrm{m}^{-3}$ ) for the entire summer period of 2015 and $18 \mu \mathrm{g} \mathrm{m}^{-3}$ (SD equal to $7 \mu \mathrm{g} \mathrm{m}^{-3}$ ) for the episode. However, when we consider only stations from Southern Poland that were under the greatest influence of pollutants from biomass burning, then these values were $13 \mu \mathrm{g} \mathrm{m}^{-3}$ (SD equal to $3 \mu \mathrm{g} \mathrm{m}^{-3}$ ) and $26 \mu \mathrm{g} \mathrm{m}^{-3}$ (SD equal to $5 \mu \mathrm{g} \mathrm{m}^{-3}$ ), respectively, for the entire period and episode.

\subsection{The Modeling System and the Experiment Design}

The general concept of the forecasting system for Poland was described in [25]. Recently, the system has been extended towards assimilation of meteorological parameters and surface observations of PM2.5 [22]. Below, we provide the most important information on the system configuration.

We used version 3.9 of the WRF-Chem model with two nested domains-an outer domain that covers Europe on a $12 \mathrm{~km} \times 12 \mathrm{~km}$ grid and an inner domain that focuses on Poland at a $4 \mathrm{~km} \times 4 \mathrm{~km}$ resolution. The mother domain has 285 and 332 grid cells in the west-east and south-north directions, respectively. We used 35 vertical levels with the lowest layer's top at about $30 \mathrm{~m}$. The model configuration includes the Noah land surface model [26], Yonsei University (YSU) boundary layer physics [27], Rapid Radiative Transfer Model for General circulation model (RRTMG) long- and short-wave radiation scheme [28], Grell 3D parameterization with radiation feedback and shallow convection, and Morrison 2-moments microphysics scheme [29]. The simulations are driven by the Global Forecasting System (GFS) meteorological data, available every $3 \mathrm{~h}$, at a $0.5^{\circ} \times 0.5^{\circ}$ spatial 
resolution. The gas phase chemistry model used in this study was the Regional Acid Deposition Model, version 2 (RADM2, [30]), while the aerosol model included the Goddard Chemistry Aerosol Radiation and Transport scheme (GOCART, [31]). The GOCART model within WRF-Chem simulates 14 aerosol species that include sulfate, dust, organic carbon, elemental carbon, sea salt, and an additional aerosol component that includes nitrate and other unspecified particles with a radius smaller than $2.5 \mu \mathrm{m}$. Two emission databases were applied in the simulations. We used the emission database developed by the Netherlands Organisation for applied scientific research (TNO MACC III) as it has the highest spatial resolution $\left(1 / 8^{\circ} \times 1 / 16^{\circ}\right.$, around $\left.7 \mathrm{~km} \times 7 \mathrm{~km}\right)$ [32] compared to other databases available for the whole of Europe. This database is used only for the area outside of Poland. For Poland itself, we used high resolution $(1 \mathrm{~km} \times 1 \mathrm{~km})$ official national data for the year 2016 provided by the Chief Inspectorate of Environmental Protection (CIEP).

We used the 3D-Var component of the Gridpoint Statistical Interpolation (GSI) system, developed at the National Centers for Environmental Prediction to integrate surface and satellite observations into modeled initial conditions. Please see a detailed description of GSI in [17,33].

The simulations were run for the period of 11-25 February 2017 (winter episode) and 1-20 August 2015 (summer episode) with chemical cycling included. We ran $48 \mathrm{~h}$ forecasts, which started at 12:00 UTC (Coordinated Universal Time). For a run with no DA, the WRF-Chem output from the last hour of the previous simulation was used to initialize the next simulation. For the DA simulations, the WRF-Chem output was modified by the GSI assimilation system.

To analyze the influence of the surface and satellite data assimilation on the modeled PM2.5 concentrations, we ran four simulations for each episode:

- $\quad$ BASE: simulation with no DA

- SURF: simulation with assimilation of surface PM2.5 observations

- MODIS: simulation with assimilation of satellite AOD observations

- SM: simulation with assimilation of both surface PM2.5 and satellite AOD data

The following standard error measures were used to validate modeled PM2.5 concentrations (please see Table 1 for a description of the statistics ): factor of two (FAC2, the fraction of points greater than 0.5 times and less than 2 times the measured value), mean bias (MB), mean gross error (MGE), normalized mean bias (NMB), normalized mean gross error (NMGE), and correlation coefficient (R). The mean statistics for all stations and the entire simulation period were calculated based on the first $24 \mathrm{~h}$ of each forecast.

Table 1. Definitions of error statistics used in the study. $O$ is for observed values and $P$ is for predicted values.

\begin{tabular}{cccc}
\hline Statistic & Formula & Range of Values & Expected Value \\
\hline Factor of Two (FAC2) & $\begin{array}{c}\text { Fraction of data that fulfil the } \\
\text { condition: } 0.5 \leq \frac{P_{i}}{O_{i}} \leq 2.0\end{array}$ & {$[0,1]$} & 1 \\
\hline Mean Bias (MB) & $M B=\frac{1}{N} \sum_{1}^{N}\left(P_{i}-O_{i}\right)$ & {$[-\overline{\mathrm{O}},+\infty]$} & 0 \\
\hline Mean Gross Error (MGE) & $M G E=\frac{1}{N} \sum_{1}^{N}\left|P_{i}-O_{i}\right|$ & {$[0,+\infty]$} & 0 \\
\hline Normalized Mean Bias (NMB) & $N M B=\frac{\sum_{i=1}^{N}\left(P_{i}-O_{i}\right)}{\sum_{i=1}^{N} O_{i}}$ & {$[-1,+\infty]$} & 0 \\
\hline Normalized Mean Gross Error (NMGE) & $N M G E=\frac{\sum_{i=1}^{N}\left|P_{i}-O_{i}\right|}{\sum_{i=1}^{N} O_{i}}$ & {$[0,+\infty]$} & 1 \\
\hline Correlation Coefficient (R) & $R=\frac{\sum_{i=1}^{N}\left(P_{i}-\bar{P}\right)\left(O_{i}-\bar{O}\right)}{\left\{\sum_{i=1}^{N}\left(P_{i}-\bar{P}\right)^{2} \sum_{i=1}^{N}\left(O_{i}-\bar{O}\right)^{2}\right\}^{\frac{1}{2}}}$ & {$[[-1,1]$} & \\
\hline
\end{tabular}

Additionally, we checked if data assimilation methods can improve the performance of the Air quality index (AQI) over Poland for the winter episode. We used the Polish environmental quality index, developed and recommended by the Chief Inspectorate of Environmental Protection and used to 
inform Polish people about air quality and, if necessary, to warn against harmful effects. We analyzed if data assimilation improves prediction of "poor" conditions, determined by PM2.5 concentrations exceeding $61 \mu \mathrm{g} \mathrm{m}^{-3}$. A "poor" index value means that it is recommended to limit outdoor activities. Air pollution can pose a risk for people in a high-risk/sensitive group, including children, the elderly and people with heart or respiratory diseases. Other people should limit staying outdoors, especially when they experience symptoms such as coughing or irritation to the throat.

We used here the value of $61 \mu \mathrm{g} \mathrm{m}^{-3}$ to convert PM2.5 concentrations into a simple binary event summarized by a $2 \times 2$ contingency table (Table 2). The table elements are hits (correct forecast and event), misses (observed but not forecasted event), false alarms (forecast but not observed event), and correct rejections (correct forecast of non-event). Based on the contingency table, the performance diagram was plotted to summarize and compare the results for four model runs. The performance diagram uses the following statistics:

- Probability of detection, calculated as: $\mathrm{POD}=\mathrm{a} /(\mathrm{a}+\mathrm{c})$

- $\quad$ Success ratio, calculated as: $S R=1-(b /(a+b))$

- Bias, calculated as: BIAS $=(a+b) /(a+c)$

- Critical success index (also known as the threat score), calculated as: CSI $=a /(a+b+c)$

Table 2. Contingency table. The counts $a, b, c$, and $d$ are the total number of hits, false alarms, misses, and correct rejections.

\begin{tabular}{ccc}
\hline & \multicolumn{2}{c}{ Event Observed } \\
\cline { 2 - 3 } Event Forecast & Yes & No \\
\hline Yes & $\mathrm{a}$ & $\mathrm{b}$ \\
No & $\mathrm{c}$ & $\mathrm{d}$ \\
\hline
\end{tabular}

\subsection{Surface PM2.5 Observations and Satellite Data}

We used the Moderate Resolution Imaging Spectrometer (MODIS) AOD 550 data from Terra and Aqua satellites. This dataset was described in detail by Wei et al. [34]. In this study, we used the $10 \mathrm{~km}$ spatial resolution level 2 (L2) retrievals. Only those retrievals marked with quality flag 2 or 3 were used for data assimilation. MODIS uses quality flags to characterize the accuracy of AOD retrievals. The quality flags range from 3 (high confidence) to 0 (low or no confidence). The quality flags are determined based on the quality and number of pixels used in the AOD algorithms. Lower confidence is related with the factors such as possibility of cloud contamination or heterogeneity of the scene [35].

Data were available in the HDF-EOS (Hierarchical Data Format - Earth Observing System) format at 5 min segments. Any retrievals that fell within the time window $+/-3 \mathrm{~h}$ around the forecast start time were used. A similar approach was used earlier by Pagowski et al. [17] for continental USA. MODIS data availability with quality flag 2 or 3 changed significantly between the winter and summer period. This is summarized in Figure 1 for the model nested domain. Mean AOD value for the winter episode was 0.14 with SD equal to 0.19 ; for the summer episode it was 0.30 and 0.19 , respectively.

The observations of ground PM2.5 concentrations from 43 stations for the winter episode of 2017 and 34 stations for the summer episode of 2015 at $1 \mathrm{~h}$ resolution were provided by the Chief Inspectorate of Environmental Protection [36]. The measurements in Poland are carried out in accordance with the methodology set out in the Directive 2008/50/EC on ambient air quality and cleaner air for Europe and in the Regulation of the Polish Minister of the Environment (13 September 2012). All automatic stations are equivalent to the reference methods and uncertainty of the particulate matter concentrations cannot be higher than $25 \%$. Mean and standard deviation values of the measured PM2.5 concentrations were provided above in the description of the episodes. Location of the stations for the winter and summer episode is shown in Figure 2. 

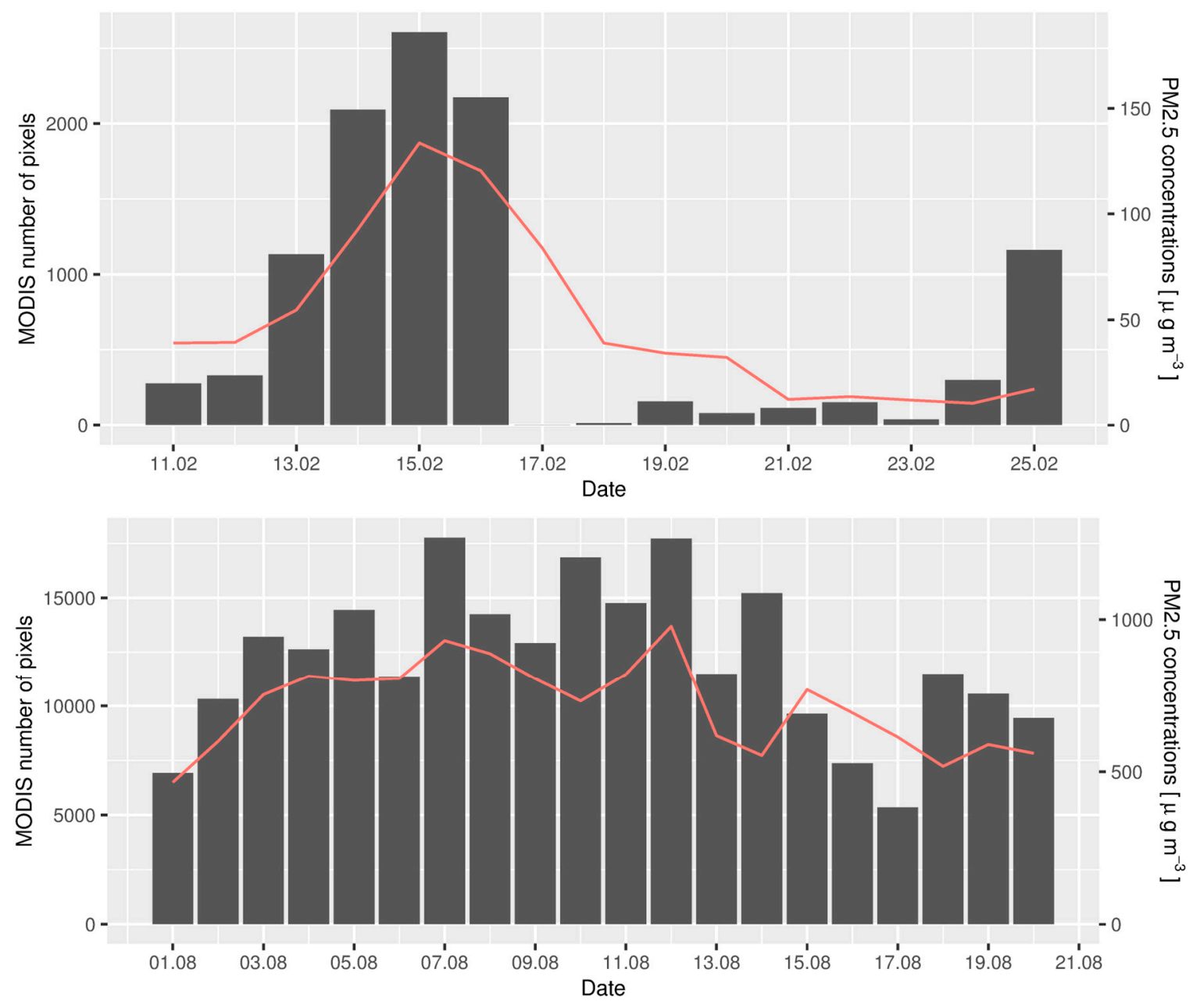

Figure 1. Moderate Resolution Imaging Spectrometer (MODIS) data availability with quality flag 2 or 3 over inner domain (Poland, $4 \mathrm{~km} \times 4 \mathrm{~km}$ ) for the winter 2017 (upper plot) and summer 2015 (lower plot) episodes. Mean observed (43 stations for winter, 34 stations for summer) particular matter (PM2.5, diameter less than $2.5 \mu \mathrm{m}$ ) concentrations are shown by the red line.

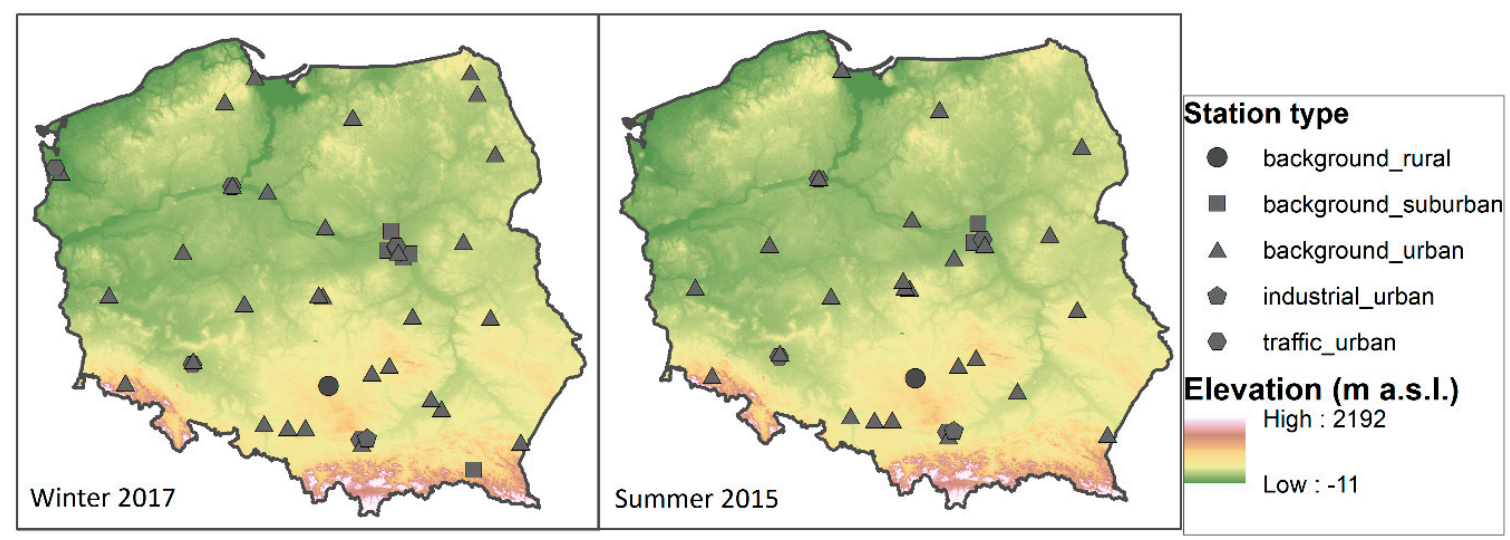

Figure 2. Location of surface observations for the winter (left) and summer seasons (right) over Poland. Station types shown by signatures. Elevation in meters above sea level (m a.s.l.) 


\section{Results}

\subsection{General Evaluation of the Models}

\subsubsection{Winter Episode}

In general, for the winter episode, the WRF-Chem model underestimates the PM2.5 measured concentrations. MB is below zero for all four runs, with the highest underestimation for the BASE simulation (Table 3). Simultaneously, for BASE, the mean gross error is twice the mean bias, which indicates that for some stations or some hours of the day, the model overestimates the observations.

The assimilation of surface PM2.5 observations reduces MB from -12.3 to $-6.7 \mu \mathrm{g} \mathrm{m}^{-3}$; however, the reduction of MGE is small, from 23.9 to $22.2 \mu \mathrm{g} \mathrm{m}^{-3}$. FAC2 and R slightly increased, from 0.71 to 0.72 and from 0.64 to 0.68 , respectively. The assimilation of MODIS AOD observations has a smaller influence on the mean model results than surface DA. NMB is reduced by 0.07 (from -0.25 to -0.18 ), whereas other statistics are reduced by 0.02 or remain unchanged. The best model performance is for the SM simulation. The error statistics for this simulation are improved, compared to BASE, SURF, and MODIS.

The performance diagram (Figure S1) confirms a positive impact of surface data assimilation on air quality predictions over Poland during the winter episode. The probability of detection of high PM2.5 concentrations, exceeding $61 \mu \mathrm{g} \mathrm{m}{ }^{-3}$ ("poor" air quality index) increased from 0.5 for the BASE to 0.70 for the SM simulation. Critical success ratio increased from 0.43 to 0.57 and BIAS improved from 0.62 to 0.93 (the perfect score is 1 ).

Table 3. Mean statistics based on hourly PM2.5 observations for the winter and summer episodes over Poland. Units for MB and MGE are $\mu \mathrm{g} \mathrm{m}^{-3}$; other statistics are dimensionless. $p$-Value $<2.2 \times 10^{-16}$ for R.

\begin{tabular}{ccccccc}
\hline & \multicolumn{7}{c}{ PM2.5 WINTER } \\
SIMULATION & FAC2 & MB & MGE & NMB & NMGE & R \\
\hline BASE & 0.71 & -12.31 & 23.85 & -0.25 & 0.48 & 0.64 \\
SURF & 0.72 & -6.71 & 22.17 & -0.14 & 0.45 & 0.68 \\
MODIS & 0.71 & -11.96 & 23.71 & -0.24 & 0.48 & 0.64 \\
SM & 0.72 & -6.58 & 22.15 & -0.13 & 0.45 & 0.68 \\
\hline & & & PM2.5 SUMMER & & \\
& FAC2 & MB & MGE & NMB & NMGE & $\mathbf{R}$ \\
\hline BASE & 0.18 & -13.34 & 14.04 & -0.71 & 0.75 & 0.16 \\
SURF & 0.34 & -10.88 & 11.65 & -0.58 & 0.62 & 0.30 \\
MODIS & 0.78 & 0.28 & 7.76 & 0.01 & 0.41 & 0.38 \\
SM & 0.78 & 0.29 & 7.76 & 0.02 & 0.41 & 0.38 \\
\hline
\end{tabular}

\subsubsection{Summer Episode}

Measured PM2.5 concentrations are underestimated by the BASE WRF-Chem simulation (Table 3). Similar values of MB $\left(-13.34 \mu \mathrm{g} \mathrm{m}^{-3}\right)$ and MGE $\left(14.04 \mu \mathrm{g} \mathrm{m}^{-3}\right)$ indicate that the model gives only a minor overestimate of the observations for this period. The correlation coefficient and FAC2 are very low and do not exceed 0.2. The assimilation of surface PM2.5 concentrations reduces MB and MGE to $-10.88 \mu \mathrm{g} \mathrm{m}^{-3}$ and $11.65 \mu \mathrm{g} \mathrm{m}^{-3}$, respectively; however, the greatest influence on the model results is produced by assimilation of MODIS AOD observations. For the MODIS run, MB is close to zero, MGE is reduced by twice as much as the BASE run, and FAC2 increases from 0.18 to 0.78 between BASE and MODIS. The correlation coefficient increases from 0.16 to 0.38 . For the SM simulation, FAC2, MGE, and $\mathrm{R}$ are the same as for the MODIS run. 


\subsection{Temporal and Spatial Variability in the Model's Performance}

Temporal changes in the model's performance are considered here in two ways. First, we analyze the mean from all stations, and the time series of PM2.5 concentrations for the entire simulation period (Figure 3). Second, we analyze variation in the mean statistics according to the lead time (Figure 4).

\subsubsection{Winter Episode}

The BASE run underestimates the measured PM2.5 concentrations for the colder period of the episode, whereas for the warmer period it reflects the observations well or slightly overestimates it (Figure 3). The WRF-Chem model results over Poland have previously shown that the model has a tendency to overestimate measured PM concentrations during warmer periods of the winter season, which is related to the fixed emissions factor and hence emissions from residential combustion being too high; for example, see [23]. The assimilation of surface observations clearly improves the model results for the colder period, with high air pollution concentrations (14-18 February 2017). DA increases the modeled PM2.5 concentrations compared to the BASE run; thus, the modeled values are closer to the observations. Simultaneously, a mismatch between models and observations is higher for SURF and MODIS than for BASE during the warmer period of the episode.
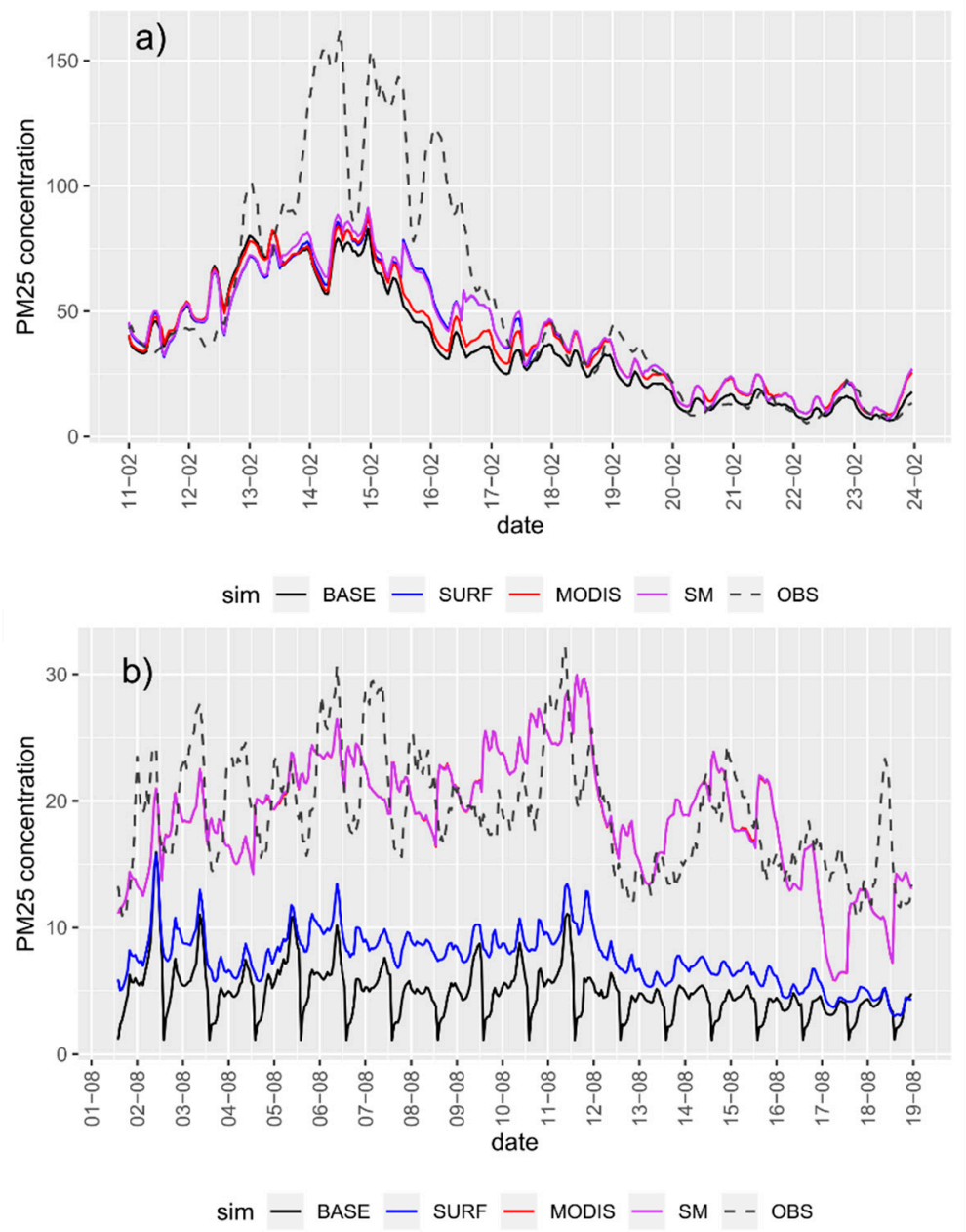

Figure 3. Time series of PM2.5 concentrations (mean from all stations) for (a) winter 2017 and (b) summer 2015 episodes over Poland. Unit: $\mu \mathrm{g} \mathrm{m}^{-3}$. Please note that there are different scales for the $\mathrm{y}$-axis for plot (a) and (b).

The highest differences between the SURF and BASE simulations are at 00 lead time: 0.13 and 2.22 for R and FAC2, respectively (Figure 4). The improvement related to DA decreases significantly 
within the first $6 \mathrm{~h}$ of the simulation. All statistics demonstrate the advantage of the SURF simulation over BASE for the first $12 \mathrm{~h}$; subsequently FAC2 and MGE are better for BASE than for simulations with DA. Differences between the MODIS and BASE simulations are smaller than between SURF and BASE. Variations in statistics for the SM simulation are similar to SURF; however, the SM simulation in general gives the best results in comparison to all other runs.
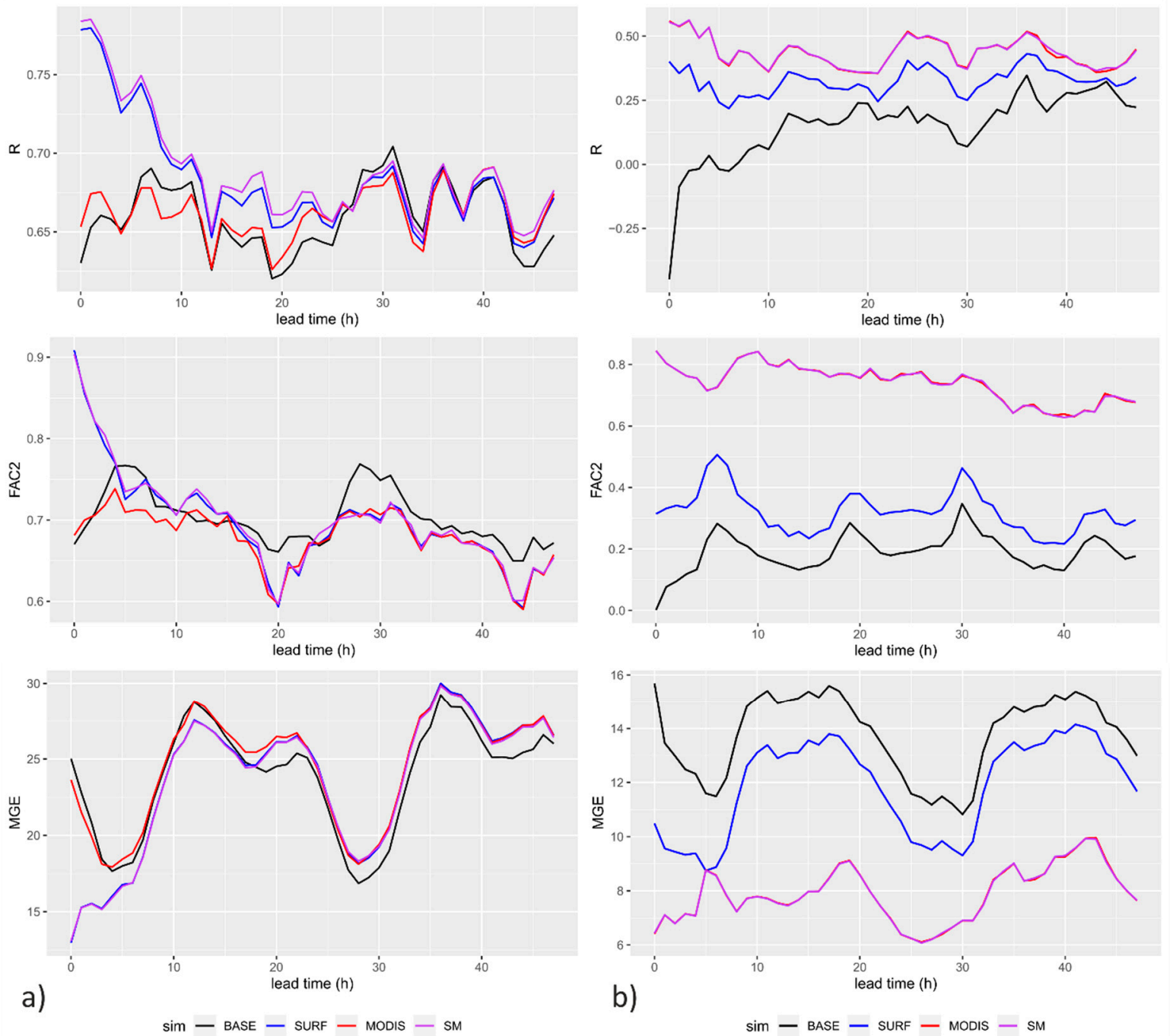

Sim - BASE - SURF - MODIS - SM

Figure 4. R, FAC2, and MGE according to the lead time for PM2.5 concentrations for (a) winter 2017 and (b) summer 2015 episodes over Poland. Unit for MGE is $\mu \mathrm{g} \mathrm{m}^{-3}$; FAC2 and R are dimensionless.

The spatial distribution of the mean bias for PM2.5 concentrations is shown in Figure 5 (other statistics in Figures S2-S4). The model simulations underestimate the measured PM2.5 concentrations at most stations. For BASE, the biggest underestimation $\left(<-15 \mu \mathrm{g} \mathrm{m}^{-3}\right)$ is in central and southwest Poland. This concerns stations in the area of low air quality related to both urban and industrial pollution as well as the station located in the valley and surrounded by local emissions sources related to things such as residential heating (Jelenia Góra station, southwest Poland). The smallest MB (within $+/-5 \mu \mathrm{g} \mathrm{m}^{-3}$ ) is in northeast Poland, which is characterized by low urbanization and industrialization. No differences in the spatial distribution of improvements between simulations with surface and MODIS DA were observed, as reported by Schwartz et al. [16] for the United States.

Improvement related to surface and satellite DA generally appears at the same station for the SURF and MODIS simulations and concerns various regions in Poland. The biggest number of stations with the smallest error (within $+/-5 \mu \mathrm{g} \mathrm{m}^{-3}$ ) is for the SM simulation. Simultaneously, there are two 
stations which show a slight overestimation (below $5 \mu \mathrm{g} \mathrm{m}^{-3}$ ) of measured PM2.5 concentrations for BASE and a higher overestimation (above $5 \mu \mathrm{g} \mathrm{m}^{-3}$ ) for SM. This situation has previously been noted by Werner et al. [22] for surface DA and might appear for areas with a significant difference in MB between stations located close to each other.

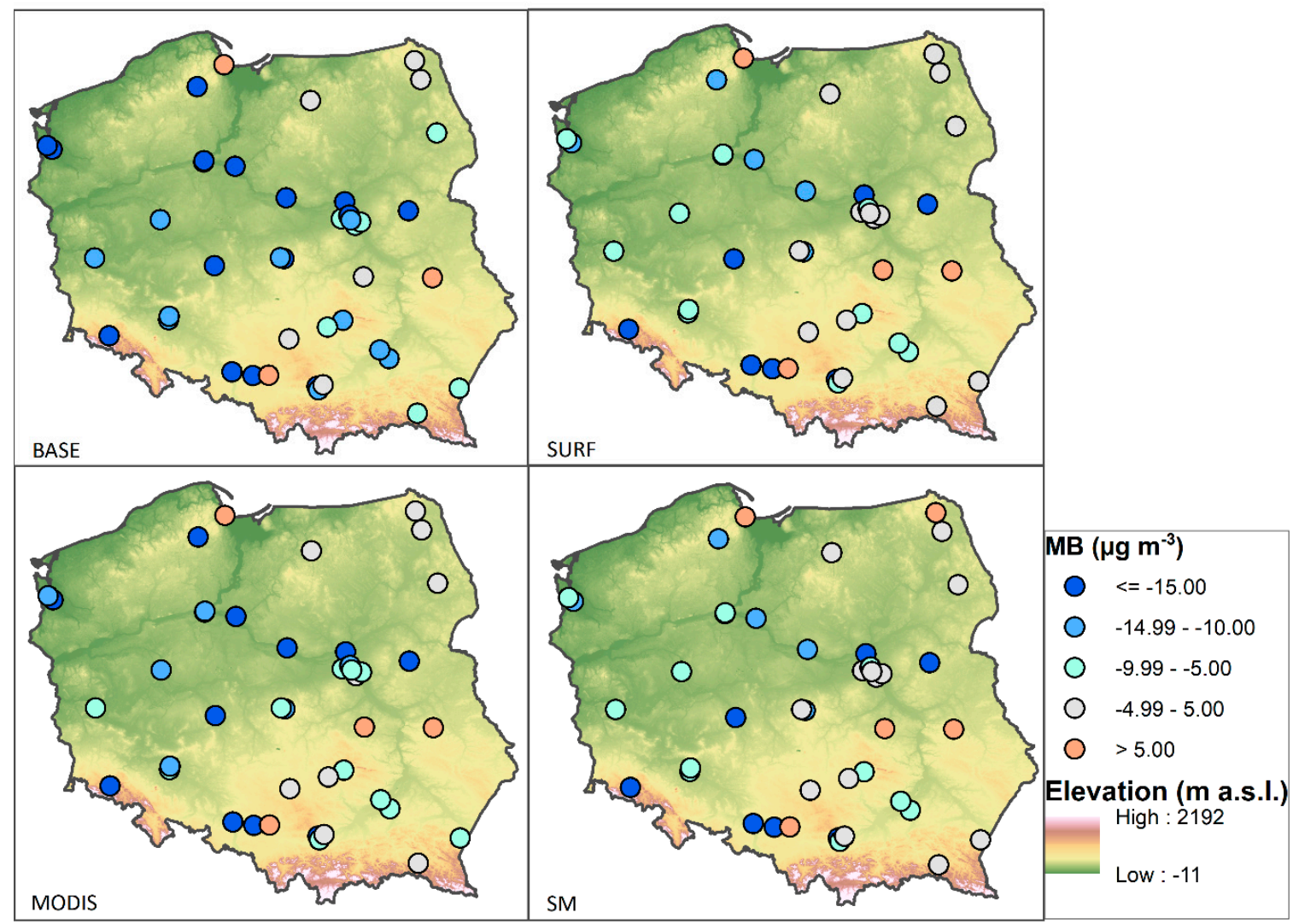

Figure 5. Spatial distributions of MB for PM2.5 concentrations for the winter 2017 episode over Poland.

Elevation in meters above sea level (m a.s.l.)

\subsubsection{Summer Episode}

The BASE run highly underestimates the measured PM2.5 concentrations for the entire simulation period of 1-20 August 2015 (Figure 3). The assimilation of surface observations increases the modeled PM2.5 concentrations and reduces the gap between the model and observations; however, the observed values are still much higher than the model. A major improvement in the model results is observed after the assimilation of MODIS AOD data. It increases the modeled values to the same level as the observations and in general reproduces the temporal changes in concentrations.

Improvements in error statistics related to data assimilation last for the entire forecast period (Figure 4); and for the entire period, error statistics for MODIS are better than for SURF. Assimilation of both types of data (surface and satellite, SM) in the same run gives a further small improvement in comparison to the MODIS run. For FAC2, differences between SM and BASE vary from 0.8 ( $00 \mathrm{~h}$ lead time) to 0.6 ( $24 \mathrm{~h}$ lead time) and 0.5 (48 h lead time). For $\mathrm{R}$, the values are respectively 1.0, 0.3 , and 02 .

The spatial distribution of the mean bias for PM2.5 concentrations is presented in Figure 6 (other statistics are presented in Figures S5-S7). The model underestimates the measured concentrations at all stations for the BASE run. For the SURF simulation, the improvement is noticeable in a few stations, which changes the class determined by the intervals. However, a more detailed analysis shows that the improvement is present in all stations for SURF, when compared to BASE (not shown). For the MODIS run, $\mathrm{MB}$ is in the class with the smallest error (within $+/-5 \mu \mathrm{g} \mathrm{m}^{-3}$ ) at most stations. For five 
stations, for which PM2.5 concentrations were slightly underestimated for BASE, MB indicates an overestimation $\left(\mathrm{MB}>5 \mu \mathrm{g} \mathrm{m}^{-3}\right)$ for the MODIS and SM run.

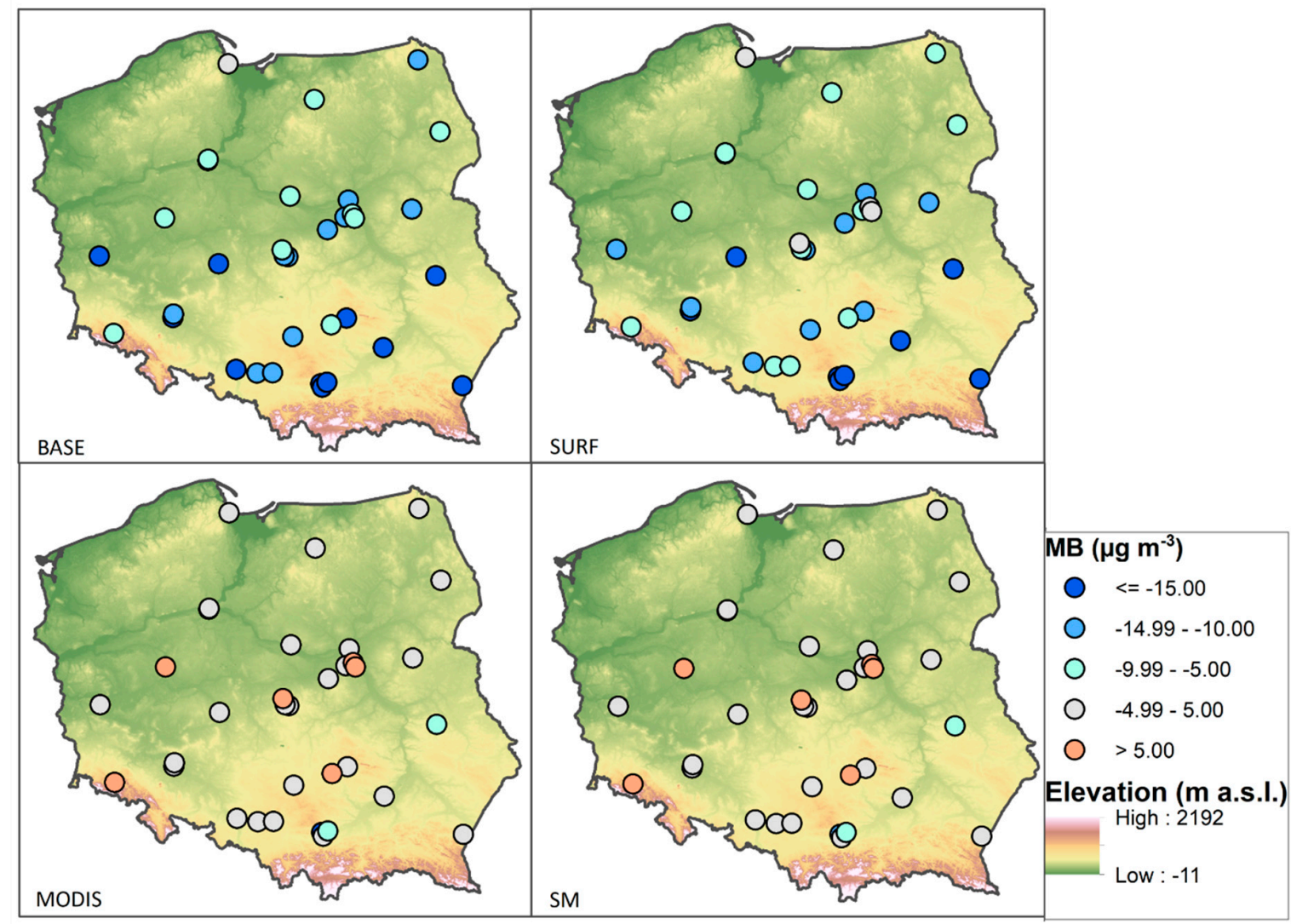

Figure 6. Spatial distributions of MB for PM2.5 concentrations for the summer 2015 episode. Elevation in meters above sea level (m a.s.l.)

\section{Discussion}

\subsection{The BASE Simulation}

The WRF-Chem model results underestimate the measured PM2.5 concentrations for the winter and summer episodes if no data assimilation is used. The underestimation is greater in summer $(\mathrm{NMB}=-0.71)$ than winter $(\mathrm{NMB}=-0.25)$. In general, for the BASE simulation the results for the summer episode are much worse than for the winter (e.g., the correlation coefficients are 0.16 and 0.64 for the summer and winter, respectively).

Previous studies have indicated various reasons for the mismatch between modeled and measured particulate matter concentrations (e.g., inaccuracy of model emissions), both in annual totals and in temporal factors applied in the model to the totals [37,38], averaging of primary emissions, and then concentrations across the model grid which is compared with monitor locations that might be more influenced by local emission sources than the grid average [39], meteorological parameters such as wind speed [40] or inaccurate initial conditions. High PM wintertime episodes in Poland are related to coal combustion and unfavorable synoptic and local-scale meteorological conditions [4]. Coal is used in residential heating, which means that the pollutants are released close to the ground and thus have a great impact on surface PM2.5 concentrations. Emissions from residential heating, due to the dispersed emission sources and different quality of fuel, are more uncertain compared to other anthropogenic emission sources such as combustion in energy and transformation industries. However, emissions might be even more uncertain for the summer period compared to winter in Poland, which is related to a higher contribution of natural emissions such as biogenic emissions, or forest fires in the 
warm season [41]. This has a major influence on the modeled PM2.5 concentrations in this study, as the GOCART chemical mechanism used here has no secondary organic aerosols included, such that biogenic emissions and forest fires have not been included in the model. Therefore, our results generally show a greater positive impact of data assimilation on the modeled PM2.5 concentrations in summer than in winter despite differences in the magnitude of the impact between the two seasons.

\subsection{Data Assimilation}

The assimilation of surface PM2.5 observations has a significant positive impact on modeled concentrations in the winter and summer episode. NMB, for instance, decreases from -0.25 to -0.14 for the winter episode and from -0.71 to -0.58 for the summer episode. However, changes for FAC2 are much greater for the summer episode (from 0.18 to 0.34 ) than for the winter episode (from 0.71 to 0.72 ).

The assimilation of satellite AOD observations has a limited positive impact on modeled PM2.5 concentrations in the winter episode but has a notable positive impact during the summer episode. MODIS run shows no improvement in FAC2, R, and NMB compared to the BASE run in winter, which is to a large degree related to meteorological conditions and low availability of the MODIS observations. On the contrary, the MODIS run gives significantly better results than BASE for the summer episode. FAC2, for instance, increased from 0.18 to 0.78 and MB improved from $-13.34 \mu \mathrm{g} \mathrm{m} \mathrm{m}^{-3}$ to $0.28 \mu \mathrm{g} \mathrm{m}^{-3}$. The SM results coincide with SURF results for the winter episode and with MODIS results for the summer episode.

Previous studies on surface PM and satellite AOD data assimilation to chemical transport models have shown a positive impact of the assimilation on modeled PM concentrations. A decrease in MB and an increase in the correlation coefficients after assimilation of the surface PM observations have been reported by Pagowski et al. and $\mathrm{Wu}$ et al. [17,42]. Hirtl et al. [2] assimilated both types of measurements-surface PM observations and satellite AOD retrievals—simultaneously and indicated that air quality forecasts with WRF-Chem were successfully improved after data assimilation. Schwartz et al. [16] showed that assimilation of AOD alone improved the surface bias over the United States more than the assimilation of PM2.5 alone after the first hour, but combined AOD and surface PM2.5 DA produced the lowest bias for all times.

Our results show that the impact of surface PM2.5 and satellite AOD data assimilation on modeled PM2.5 concentrations can vary considerably for the same region depending on the season, the meteorological conditions, and availability of satellite data. A higher positive impact of DA in Central or Eastern Europe is in general expected for the summer season, for which satellite data are more readily available and emissions more uncertain than in winter. When local domestic emission sources are the major contributor to air quality during winter, surface measurement DA has a more significant impact on forecast quality.

As to the temporal variability of the model's performance, our study shows that a positive impact of surface PM2.5 and satellite AOD data assimilation stays for the entire forecast lead time (48 h). However, for the winter episode, the improvement related to DA decreases significantly within the first 6-12 h of simulation. For example, FAC2 changes from 0.92 (00 lead time) to 0.72 (12 lead time) for the SM run. This might suggest considerable uncertainty in relation to the local emission inventory, both in terms of its spatial and temporal allocation. For the summer episode, the improvement related to DA stays longer than that in winter-FAC2 is equal to 0.85 at 00 lead time and stays at a level above 0.75 for the next $30 \mathrm{~h}$.

A general tendency showing the greatest improvement at the start of assimilation and then diminishing relatively fast with an increase in forecasted lead time was reported by Jiang et al., Li et al., and Wu et al. [12,15,42]. Schwartz et al. [16] showed that after the first hour of simulation, assimilating the satellite AOD alone reduced the bias more than assimilating PM2.5 alone. In the first $6 \mathrm{~h}$ of their simulations, PM2.5 DA, with or without AOD DA, produced the highest R; thereafter, R was best when both AOD and PM2.5 were assimilated. They have also shown that up to about $42 \mathrm{~h}$, the experiment with both PM2.5 and AOD assimilation produced the smallest bias, illustrating the 
benefit of assimilating observations from multiple sources. This result agrees with our results-SM simulations usually have the best error statistics, which are close to the SURF in winter and close to MODIS in summer.

\section{Summary and Conclusions}

We used the GSI system to assimilate surface PM2.5 concentrations and satellite total $550 \mathrm{~nm}$ AOD data to the WRF-Chem model. The analysis was undertaken for Poland, which is known for its low air quality, especially in the winter season. The simulations were run for two episodes, which have been previously discussed in the literature [23,24]. The first episode ran from 11-25 February 2017 and the second selected episode from 1-20 August 2015. We chose these episodes for two main reasons. First, they were interesting because of the meteorological and emission conditions. The first episode consisted of two periods: (1) the first period had anticyclone conditions, low air temperatures, high anthropogenic emissions from residential heating, and high measured PM2.5 concentrations; (2) the second period had the advection of warm air masses, lower anthropogenic emissions, higher wind speed, and in general conditions unfavorable for accumulation of pollutants. The second episode was chosen during an unusually warm month in Poland, with several episodes of elevated AOD observed in Southern Poland and the influence of long-range transport of biomass burning products. The second reason for choosing these episodes was poor forecast performance with the WRF-Chem model, which was originally run with no observational data assimilation. The aim of the study was to test if the model performance could be improved for these periods with application of data assimilation techniques.

The WRF-Chem model was run four times for each episode. In the first simulation, we used no DA (BASE), and in the next three simulations we used surface PM2.5 concentrations (SURF), satellite AOD (MODIS), and surface and satellite (SM) data for assimilation, respectively. The results for the two selected episodes over Poland show that:

- Assimilation of surface and satellite data improves the model statistics for PM2.5 concentrations calculated for the winter and summer episodes in Poland. This is indicated by a smaller bias and higher correlation coefficient as well as factor of two for simulations with DA in comparison to BASE.

- Assimilation of surface observations has a greater positive impact on the mean model results than assimilation of satellite data in the winter episode; on the contrary, assimilation of satellite data has a greater positive impact during the summer episode. Simultaneously, the best model performance for both seasons' episodes is for simulations with both surface and satellite data assimilated. It confirms that simultaneous DA of different aerosol observations can work synergistically to improve the aerosol forecasts.

- All DA simulations show the biggest improvement in comparison to BASE at 00 lead time, and thereafter the relation between simulations with DA and BASE varies for the next few hours of simulations. In general, the positive effect of DA is greater and lasts longer in the summer episode than in winter.

We should emphasize here that our study is based on relatively short episodes, lasting no longer than 2-3 weeks and therefore has some limitations compared to long lasting simulations, such as annual runs, which can show the average role of surface and satellite data assimilation on the modeling results. However, our results have also a more general message, not strictly related to the selected episodes. We show that there are some limitations in the application of satellite MODIS data, both as a source of information for data assimilation in deterministic models such as WRF-Chem and for other techniques that use AOD as a predictor of PM2.5 concentrations (e.g., regression models). Meteorological conditions, especially during the winter period, are not conducive to high quality MODIS AOD mainly due to cloudiness. That is why this source of information has limited applicability in air quality forecasting at a high temporal resolution for the winter season. The situation is different 
for surface observations, as the number of stations is usually relatively constant during a longer period for a country and availability of surface PM2.5 concentrations does not depend on meteorological conditions. Obviously, different countries have different coverage and spatial distribution of surface PM2.5 observations and modeling studies dedicated to data assimilation are necessary to find out the capability of observational data in improving models' performance. To some degree the number of available stations might also vary from day to day due to for example, technical reasons, which can influence the modeling results.

Supplementary Materials: The following are available online at http://www.mdpi.com/2072-4292/11/20/2364/s1, Figure S1: Performance diagram summarizing the success ratio, probability of detection, bias (dashed lines with labels on the outward extension of the line) and critical success ratio (solid lines) for detecting PM2.5 concentrations above $61 \mathrm{\mu g} \mathrm{m}^{-3}$ ("poor" air quality) by the BASE, SURF, MODIS and SM simulations over Poland for the winter 2017 episode over Poland. The perfect model lies in the upper right corner, Figure S2: Spatial distributions of MGE for PM2.5 concentrations for the winter 2017 episode over Poland., Figure S3: Spatial distributions of FAC2 for PM2.5 concentrations for the winter 2017 episode over Poland., Figure S4: Spatial distributions of R for PM2.5 concentrations for the winter 2017 episode over Poland., Figure S5: Spatial distributions of MGE for PM2.5 concentrations for the summer 2015 episode over Poland., Figure S6: Spatial distributions of FAC2 for PM2.5 concentrations for the summer 2015 episode over Poland., Figure S7: Spatial distributions of R for PM2.5 concentrations for the summer 2015 episode over Poland.

Author Contributions: Conceptualization, M.W.; data curation, M.K.; funding acquisition, M.W.; investigation, M.W.; software, M.W., M.K., and J.G.; validation, M.W.; visualization, M.W. and M.K.; writing-original draft, M.W.; writing-review and editing, M.K. and J.G.

Funding: This research was funded by the Polish National Science Centre project no. UMO-2016/23/B/ST10/01797.

Acknowledgments: TNO MACC III data base at $1 / 8^{\circ} \times 1 / 16^{\circ}$ was provided free of charge by TNO Netherlands (https://www.tno.nl/en/about-tno/contact/, direct contact to TNO, Kuenen et al., 2014). Emissions data for Poland $(1 \mathrm{~km} \times 1 \mathrm{~km}$ and $500 \mathrm{~m} \times 500 \mathrm{~m}$ for cities) were provided by the Chief Inspectorate of Environmental Protection (http://www.gios.gov.pl/en/, direct contact to the institution). These data were prepared for the year 2016 within the project: "Supporting the air quality assessment system with application of modeling of PM10, PM2.5, SO2, NO2, B(a)P for the years 2015, 2016 and 2017".

Conflicts of Interest: The authors declare no conflicts of interest.

\section{References}

1. Marécal, V.; Peuch, V.-H.; Andersson, C.; Andersson, S.; Arteta, J.; Beekmann, M.; Benedictow, A.; Bergström, R.; Bessagnet, B.; Cansado, A.; et al. A regional air quality forecasting system over Europe: The MACC-II daily ensemble production. Geosci. Model Dev. 2015, 8, 2777-2813. [CrossRef]

2. Hirtl, M.; Mantovani, S.; Krüger, B.C.; Triebnig, G.; Flandorfer, C.; Bottoni, M.; Cavicchi, M. Improvement of air quality forecasts with satellite and ground based particulate matter observations. Atmos. Environ. 2014, 84, 20-27. [CrossRef]

3. Krynicka, J.; Drzeniecka-Osiadacz, A. Analysis of variability in PM10 concentration in the Wroclaw agglomeration. Pol. J. Environ. Stud. 2013, 22, 1091-1099.

4. Reizer, M.; Juda-Rezler, K. Explaining the high PM10 concentrations observed in Polish urban areas. Air Qual. Atmos. Health 2016, 9, 517-531. [CrossRef]

5. Pope, C.A.; Ezzati, M.; Dockery, D.W. Fine-particulate air pollution and life expectancy in the United States. N. Engl. J. Med. 2009, 360, 376-386. [CrossRef]

6. Kampa, M.; Castanas, E. Human health effects of air pollution. Environ. Pollut. 2008, 151, 362-367. [CrossRef]

7. Amato, G.D.; Cecchi, L.; Amato, M.D.; Liccardi, G. Urban Air Pollution and Climate Change as Environmental Risk Factors of Respiratory Urban Air Pollution and Climate Change as Environmental Risk Factors of Respiratory Allergy: An Update Environmental Risk Factors of Respiratory Allergy: An Update. J. Investig. Allergol. Clin. Immunol. 2010, 20, 95-102.

8. Grewling, Ł.; Fratczak, A.; Kostecki, Ł.; Nowak, M.; Szymańska, A.; Bogawski, P. Biological and Chemical Air Pollutants in an Urban Area of Central Europe: Co-exposure Assessment. Aerosol Air Qual. Res. 2019, 19, 1526-1537. [CrossRef]

9. Baldacci, S.; Maio, S.; Cerrai, S.; Sarno, G.; Ba1z, N.; Simoni, M.; Annesi-Maesano, I.; Viegi, G. Allergy and asthma: Effects of the exposure to particulate matter and biological allergens. Respir. Med. 2015, 109, 1089-1104. [CrossRef] 
10. Huynen, M.; Menne, B.; Behrendt, H.; Bertollini, R.; Bonini, S.; Brandao, R. Phenology and Human Health: Allergic Disorders; Health and Global Environmental Change: Rome, Italy, 2003.

11. Heinzerling, L.M.; Burbach, G.J.; Edenharter, G.; Bachert, C.; Bindslev-Jensen, C.; Bonini, S.; Bousquet, J.; Bousquet-Rouanet, L.; Bousquet, P.J.; Bresciani, M.; et al. GA(2)LEN skin test study I: GA(2)LEN harmonization of skin prick testing: Novel sensitization patterns for inhalant allergens in Europe. Allergy 2009, 64, 1498-1506. [CrossRef]

12. Li, Z.; Zang, Z.; Li, Q.B.; Chao, Y.; Chen, D.; Ye, Z.; Liu, Y.; Liou, K.N. A three-dimensional variational data assimilation system for multiple aerosol species with WRF/Chem and an application to PM2.5 prediction. Atmos. Chem. Phys. 2013, 13, 4265-4278. [CrossRef]

13. Zang, Z.; Hao, Z.; Li, Y.; Pan, X.; You, W.; Li, Z.; Chen, D. Background error covariance with balance constraints for aerosol species and applications in variational data assimilation. Geosci. Model Dev. 2016, 9 , 2623-2638. [CrossRef]

14. Dumitrache, R.C.; Iriza, A.; Maco, B.A.; Barbu, C.D.; Hirtl, M.; Mantovani, S.; Nicola, O.; Irimescu, A.; Craciunescu, V.; Ristea, A.; et al. Study on the influence of ground and satellite observations on the numerical air-quality for PM10 over Romanian territory. Atmos. Environ. 2016, 143, 278-289. [CrossRef]

15. Jiang, Z.; Liu, Z.; Wang, T.; Schwartz, C.S.; Lin, H.C.; Jiang, F. Probing into the impact of 3DVAR assimilation of surface PM10 observations over China using process analysis. J. Geophys. Res. Atmos. 2013, 118, 6738-6749. [CrossRef]

16. Schwartz, C.S.; Liu, Z.; Lin, H.C.; McKeen, S.A. Simultaneous three-dimensional variational assimilation of surface fine particulate matter and MODIS aerosol optical depth. J. Geophys. Res. Atmos. 2012, 117, 1-22. [CrossRef]

17. Pagowski, M.; Liu, Z.; Grell, G.A.; Hu, M.; Lin, H.-C.; Schwartz, C.S. Implementation of aerosol assimilation in Gridpoint Statistical Interpolation v. 3.2 and WRF-Chem v. 4.3.1. Geosci. Model Dev. Discuss. 2014, 7, 2483-2500. [CrossRef]

18. Feng, S.; Jiang, F.; Jiang, Z.; Wang, H.; Cai, Z.; Zhang, L. Impact of 3DVAR assimilation of surface PM2.5observations on PM2.5forecasts over China during wintertime. Atmos. Environ. 2018, 187, $34-49$. [CrossRef]

19. Bocquet, M.; Elbern, H.; Eskes, H.; Hirtl, M.; Aabkar, R.; Carmichael, G.R.; Flemming, J.; Inness, A.; Pagowski, M.; Pérez Camaño, J.L.; et al. Data assimilation in atmospheric chemistry models: Current status and future prospects for coupled chemistry meteorology models. Atmos. Chem. Phys. 2015, 15, 5325-5358. [CrossRef]

20. Barker, D.M.; Huang, W.; Guo, Y.-R.; Bourgeois, A.J.; Xiao, Q.N. A Three-Dimensional Variational Data Assimilation System for MM5: Implementation and Initial Results. Mon. Weather Rev. 2004, 132, 897-914. [CrossRef]

21. Mazzarella, V.; Maiello, I.; Capozzi, V.; Budillon, G.; Ferretti, R. Comparison between 3D-Var and 4D-Var data assimilation methods for the simulation of a heavy rainfall case in central Italy. Adv. Sci. Res. 2017, 145194, 271-278. [CrossRef]

22. Werner, M.; Kryza, M.; Pagowski, M.; Guzikowski, J. Assimilation of PM2.5 ground base observations to two chemical schemes in WRF-Chem-The results for the winter and summer period. Atmos. Environ. 2019, 200, 178-189. [CrossRef]

23. Kryza, M.; Werner, M.; Dore, A. Application of degree-day factors for residential emission estimate and air quality forecasting. Int. J. Environ. Pollut. 2019, in press.

24. Szkop, A.; Pietruczuk, A. Analysis of aerosol transport over southern Poland in August 2015 based on a synergy of remote sensing and backward trajectory techniques. J. Appl. Remote Sens. 2017, 11, 016039. [CrossRef]

25. Werner, M.; Kryza, M.; Ojrzyńska, H.; Skjøth, C.A.; Wałaszek, K.; Dore, A.J. Application of WRF-Chem to forecasting PM10 concentration over Poland. Int. J. Environ. Pollut. 2015, 58, 280-292. [CrossRef]

26. Chen, F.; Dudhia, J. Coupling an Advanced Land Surface-Hydrology Model with the Penn State-NCAR MM5 Modeling System. Part I: Model Implementation and Sensitivity. Mon. Weather Rev. 2001, 129, 569-585. [CrossRef]

27. Hong, S.-Y.; Noh, Y.; Dudhia, J. A New Vertical Diffusion Package with an Explicit Treatment of Entrainment Processes. Mon. Weather Rev. 2006, 134, 2318-2341. [CrossRef] 
28. Iacono, M.J.; Delamere, J.S.; Mlawer, E.J.; Shephard, M.W.; Clough, S.A.; Collins, W.D. Radiative forcing by long-lived greenhouse gases: Calculations with the AER radiative transfer models. J. Geophys. Res. 2008, 113, D13103. [CrossRef]

29. Morrison, H.; Thompson, G.; Tatarskii, V.; Morrison, H.; Thompson, G.; Tatarskii, V. Impact of Cloud Microphysics on the Development of Trailing Stratiform Precipitation in a Simulated Squall Line: Comparison of One- and Two-Moment Schemes. Mon. Weather Rev. 2009, 137, 991-1007. [CrossRef]

30. Stockwell, W.R.; Middleton, P.; Chang, J.S.; Tang, X. The second generation regional acid deposition model chemical mechanism for regional air quality modeling. J. Geophys. Res. 1990, 95, 16343. [CrossRef]

31. Chin, M.; Ginoux, P.; Kinne, S.; Torres, O.; Holben, B.N.; Duncan, B.N.; Martin, R.V.; Logan, J.A.; Higurashi, A.; Nakajima, T. Tropospheric Aerosol Optical Thickness from the GOCART Model and Comparisons with Satellite and Sun Photometer Measurements. J. Atmos. Sci. 2002, 59, 461-483. [CrossRef]

32. Kuenen, J.J.P.; Visschedijk, A.J.H.; Jozwicka, M.; Denier van der Gon, H.A.C. TNO-MACC_II emission inventory; a multi-year (2003-2009) consistent high-resolution European emission inventory for air quality modelling. Atmos. Chem. Phys. 2014, 14, 10963-10976. [CrossRef]

33. Pagowski, M.; Grell, G.A.; McKeen, S.A.; Peckham, S.E.; Devenyi, D. Three-dimensional variational data assimilation of ozone and fine particulate matter observations: Some results using the Weather Research and Forecasting-Chemistry model and Grid-point Statistical Interpolation. Q. J. R. Meteorol. Soc. 2010, 136, 2013-2024. [CrossRef]

34. Wei, J.; Li, Z.; Peng, Y.; Sun, L. MODIS Collection 6.1 aerosol optical depth products over land and ocean: Validation and comparison. Atmos. Environ. 2018, 201, 428-440. [CrossRef]

35. Sayer, A.M.; Hsu, N.C.; Bettenhausen, C.; Jeong, M.J. Validation and uncertainty estimates for MODIS Collection 6 "deep Blue" aerosol data. J. Geophys. Res. Atmos. 2013, 118, 7864-7872. [CrossRef]

36. Chief Inspectorate for Environmental Protection. Available online: http://powietrze.gios.gov.pl (accessed on 15 January 2019).

37. Lin, C.; Heal, M.R.; Vieno, M.; MacKenzie, I.A.; Armstrong, B.G.; Butland, B.K.; Milojevic, A.; Chalabi, Z.; Atkinson, R.W.; Stevenson, D.S.; et al. Spatiotemporal evaluation of EMEP4UK-WRF v4.3 atmospheric chemistry transport simulations of health-related metrics for NO2, O3, PM10, and PM2. 5 for 2001-2010. Geosci. Model Dev. 2017, 10, 1767-1787. [CrossRef]

38. Saide, P.E.; Spak, S.N.; Carmichael, G.R.; Mena-Carrasco, M.A.; Yang, Q.; Howell, S.; Leon, D.C.; Snider, J.R.; Bandy, A.R.; Collett, J.L.; et al. Evaluating WRF-Chem aerosol indirect effects in Southeast Pacific marine stratocumulus during VOCALS-REx. Atmos. Chem. Phys. 2012, 12, 3045-3064. [CrossRef]

39. Dore, T.; Kryza, M.; Hall, J.R.; Hallsworth, S.; Keller, V.J.D.; Vieno, M.; Sutton, M.A. The influence of model grid resolution on estimation of national scale nitrogen deposition and exceedance of critical loads. Biogeosciences 2012, 9, 1597-1609. [CrossRef]

40. Aksoyoglu, S.; Keller, J.; Barmpadimos, I.; Oderbolz, D.; Lanz, V.A.; Prévăt, A.S.H.; Baltensperger, U. Aerosol modelling in Europe with a focus on Switzerland during summer and winter episodes. Atmos. Chem. Phys. 2011, 11, 7355-7373. [CrossRef]

41. Werner, M.; Kryza, M.; Wind, P. High resolution application of the EMEP MSC-W model over Eastern Europe-Analysis of the EMEP4PL results. Atmos. Res. 2018, 212, 6-22. [CrossRef]

42. Wu, J.B.; Xu, J.; Pagowski, M.; Geng, F.; Gu, S.; Zhou, G.; Xie, Y.; Yu, Z. Modeling study of a severe aerosol pollution event in December 2013 over Shanghai China: An application of chemical data assimilation. Particuology 2015, 20, 41-51. [CrossRef]

(C) 2019 by the authors. Licensee MDPI, Basel, Switzerland. This article is an open access article distributed under the terms and conditions of the Creative Commons Attribution (CC BY) license (http://creativecommons.org/licenses/by/4.0/). 